\title{
Judging credential of Medical teachers through Publication, How far it is fruitful?
}

Submitted: 13-04-2018

Revised: 18-04-2018

Published: 01-05-2018

The Medical Council of India (MCI) must be applauded for its efforts to introduce definitive criteria for appointments and promotions for teachers in medical institutions from time to time. Lately on June $8^{\text {th }} 2017^{1}$ a new amendment was made which stated, only first author and corresponding author would be considered for promotions. Let's assume that MCI have made this criterion with an aim of enhancing the quality of teaching and subsequently the excellence of medical graduates and passing out post graduates.

However with the views of the current medical teachers in medical college by feedback, this criterion has not fulfilled the purpose of increasing standards of medical educations and educators. There are some issues which still need to be defined and addressed. Firstly are all the new medical colleges who obtains letter of permission to launch new medical college with an intake of fresh medical students, does fulfill the criteria and norms as per MCI guidelines, ${ }^{2}$ and are they well equipped? Most of the new medical colleges lack basic facilities, and due to mushroom growth of medical colleges in India whether the quality is checked thoroughly before granting them the letter of permission. ${ }^{3}$

Secondly there is a lack of innovative teaching methodologies as still we are sticking to decades back teaching methodologies and curriculum which is old and has not been refined considering the needs of current medical technologies. ${ }^{4}$ Thirdly due to ghost faculties, the students are not exposed to good teachers and they are taught by junior cadre teachers who themselves are in learning process. ${ }^{5,6}$ Fourthly are the teachers assessed by students in term of their teaching standard, what methodologies of teaching assessment are adopted to measure the caliber of teaching? ${ }^{7}$

In this editorial, I will mainly focus on one of the criteria of appointment and promotion of teachers in medical college with regard to their research publication. The MCI on September $3^{\text {rd }} 2015$ stated its requirement that research publications is a must for promotion and appointment of teacher. ${ }^{8}$ Initially only first and second author was considered
Access this article online

Website:

http://nepjol.info/index.php/AJMS

DOI: 10.3126/ajms.v9i3.19618

E-ISSN: 2091-0576

P-ISSN: 2467-9100

for grading but very soon it was amended and now as per the latest norms only first author and corresponding author is considered for grading points for promotions.

Secondly, it was also recommended that only journals with printed edition indexed Scopus, PubMed, Medline, Embase/Excerpta Medica, Index Medicus and Index Copernicus could be considered as a platform to publish original research articles in order to minimize plagiarism. Let us discuss these points based on the MCI criteria for promotions and consideration as a faculty. No doubt that MCI has made great efforts to ensure the quality of publication in indexed journals as this amendment can ensure that a good quality articles are published which are the criteria for grading teachers and promotions as well.

This is a very good initiative by MCI as indexing indicates that the journal undoubtedly meets basic standards and quality, specific to a particular index. Now let's have a closer look about the indexing criteria made by MCI. Accepting on PubMed indexed journals would exclude some quality research in Allied health sciences, such as basic sciences, humanities and social sciences. Furthermore there are too many journals which seek articles for publications and they are also named as Predator or psuedojournals.

Secondly considering only those journals with printed version is another flaw ${ }^{9}$ and demerit as there are very high impact journals namely PLoS, BioMed Central which are only e-journals though they are far better than some printed journals. So does this mean that article published in these only e-journals cannot be considered for grading teachers, in this era of digital transformation? 
Thirdly, about considering only first author and corresponding author as a grading point for promotion. Usually first author is the student or researcher who is involved in the research work. They are also often referred to as presenting author. The presenting author is solely responsible for doing the research practically along with the co-authors who might assist in the research work. The presenting author is also responsible for preparing the manuscript and analyzing the research output.

Corresponding author is usually the senior author who is responsible for the intellectual input, study design and approval of protocol of the study. Furthermore he is also responsible for manuscript proof corrections, final approval before submission of the article and the entire correspondence during the article submission. This is usually practiced in most cases. In some when it is a collaborative work with other institutes, the actual researcher and corresponding author remains the same, but the number of co-authors depends on the entire team of people involved in the research.

I would like to comment on one aspect. It happens in some institutes that the actual researchers become second author or even co-author which is just unethical and injustice on the part of actual researcher or student. But this practice is prevalent in some institutions and researchers or the students are bound or compelled to it being the beginners. Another situation which I have noticed is that head of the institute or director is a part of every research throughputs no matter it is relevant or irrelevant to him/her. So this kind of practice is prevalent now-a-days.

So by now we can understand how difficult is a part of the teacher to be the first author or a corresponding author in original research article which is considered as grading points for teacher's assessment for promotions. Ideally this should not be the only criteria for teacher's credibility, as the roles of faculties in medical institutions are many. In developed countries of the West, research is an integrated part of teacher's activities. Some of the teacher's appointment is based on either for research or for teaching and they are labeled as Teaching- Teaching (TT), Teaching-Research (TR) or Research-Research (RR). So if a teacher appointed as RR, they are involved in full-time research. They are bound to publish at least five original articles in Indexed journal in a year through their research output. So it means, that the employers assess their employee (teachers) based on their area of interest and not merely by research publication.

In Western countries the institutes are well-funded and furnished laboratories, they receive grants from government and agencies. However the situation in India is quite different. Even though you find every small hospitals and private medical colleges name themselves as "research centers" or "research institute", hardly one can find any research virtually happens. Since private medical colleges are mostly run on a business-model, research activities are not that hard pressed and there is no funding for research by the management as they only burn holes in the pockets without giving them ay financial gains.

Faculties often obtain research grants from Government aided funding agencies Indian Council of Medical Research ${ }^{10}$ or any other eternal grants or raise funds by their own research team as hardly research grants are provided to new medical college as their selection process is highly competitive, makes teachers complaisance and only few manage to undertake high quality research. Since there is an ongoing trend of either to publish or perish, we hardly find the result of genuine or unadulterated work in the original research publications.

The other side of this aspect is, are all research work monitored or auditing of research is done. In absence of any monitoring, the data of the research could be easily manipulated. It is possible to generate a research article without doing any work at all. Tactics of exchange authorship is adopted to minimize efforts and stress in publishing original research article. The simple way is "you make me second author in your publication and I make you second author in my publication" which makes them deemed fit for grading them in the event of promotions. By this way two individuals with a single research article can get benefit of two original publications.

Fraud in scientific publications has a deep impact and consequences, as the results of the research and applied on patient care. I have experienced that when articles submitted and found flaws in data collection or even say errors in determining the sample size of the study. We ask the author to re-submit after adding more samples with continued study in the same line; the author re-submits their articles in very less time with higher sample size in the study. It is understood that there is merely any further research to it but it is just cooked up data to increase the sample size in order to validate the results.

The issues of such fraudulent research are still prevailing and there is a need of strict vigilance and action against such acts. The role of Institutional Ethical Committee, Research Committee is to investigate the falsification and fabrication in such research.

The author's should ensure that article submitted to journal for publication is true to the best of their knowledge and it is based on scientific data, from the research outputs. There should be author's contribution in all articles, to determine the contribution of all authors in the article. Editors should 
have the rights to retract any published articles if suspected of any such fabrications without the consent of author or their affiliated institutions.

When we really get down deep in the research involvements, we find research is a conglomerate of ideas and thought processes which requires dedications. Right from designing the concept of the study, its relevant literature search, obtaining research grants, preparing setup for the study, data collection, analysis, drafting the research outcomes, and finally publication. Is it possible that all these can be done by a single individual who happens to be a first author or the presenting author?

Moreover, time management of teachers in medical college is so hard pressed as they are supposed to do participate in teaching, conducting practical, conducting fortnight student's assessment test, marking answer papers, preparing mark-sheet, tabulations and so on. This makes the teachers so much pre-occupied in their regular routine work with the compulsion of doing research makes them to adopt any means to publish research articles.

By the above facts we need time to rethink whether teacher's credentials should merely be assessed in terms of research publications or adopted some other methodologies to grade the teachers in a medical college.

\section{REFERENCES}

1. Medical Council of India. Amendment Notification. New Delhi; 05 June. 2017. http://old.mciindia.org/Rules-and-Regulation/ Gazette \%20Notifications \% 20-\%20Amendments/TEQ08.06.2017.pdf
2. N, Ananthakrishnan; K, Shanthi A. Attempts at regulation of medical education by the $\mathrm{MCl}$ : issues of unethical and dubious practices for compliance by medical colleges and some possible solutions. Indian Journal of Medical Ethics, [S.I.], v. 9, n. 1, p. 37, nov. 2016. ISSN 0975-5691. Avaialble at: <http://ijme.in/articles/ attempts-at-regulation-of-medical-education-by-the-mci-issuesof-unethical-and-dubious-practices-for-compliance-by-medicalcolleges-and-some-possible-solutions/>. Date accessed: 18 Apr. 2018.

3. https://indiankanoon.org/doc/1765134

4. D. Vasundhara Devi, M. Kiran Deedi. Teaching and Learning Methodology in Medical Education: An Analysis-in GSL Medical College, Rajahmundry, A. P. Journal of Evolution of Medical and Dental Sciences 2015; 4(72): 12557-12565.

5. https://www.sundayguardianlive.com/news/10491-14-medicalcolleges-showed-ghost-faculty-got-hit

6. http://www.thehindu.com/news/cities/Thiruvananthapuram/mcito-act-against-ghost-faculty/article8598713.ece

7. MS Tullu and S Karande. Quality research in Indian medical colleges and teaching institutions: The need of the hour. J Postgrad Med 2016; 62(4): 213-215.

8. Indian editors urge medical council to rethink publication guidelines for academic promotions. BMJ 2016; 352 doi: https:// doi.org/10.1136/bmj.i344 (Published 21 January 2016)

9. http://www.tribuneindia.com/news/punjab/community/mci-saysno-to-papers-in-e-journals/135803.html

10. Kumar, Arun; Gangopadhyay, Dibyendu. Need of Research Oriented Approach in Medical Education in India. Asian Journal of Bio-Medical Research (ISSN:2454-6275), [S.I.], v. 2, n. 1, mar. 2016. ISSN 2454-6275. Available at: <http://pmindexing.com/ journals/index.php/AJBR/article/view/964>.

\section{Arun Kumar}

Editor-in-Chief, Asian Journal of Medical Sciences, Professor, Department of Biochemistry, Jagannath Gupta Institute of Medical Sciences, Buita, Budge Budge, Kolkata - 700 137, West Bengal, India

\footnotetext{
Authors Contribution:

AK- Preparation of script, editing, referencing and final approval.

Orcid ID:

Dr. Arun Kumar- (1) http://orcid.org/0000-0002-8800-0296

Source of Support: Nill, Conflict of Interest: None declared.
} 